\title{
Formation Needs of Family Practitioners and Care Needs of Islamic Patients
}

\author{
Rosa Gallelli ${ }^{1}$, Pasquale Renna ${ }^{2}$ \\ Faculty of Literature, University of Bari "Aldo Moro", Italy", \\ Department of Public Medicine, University of Bari “Aldo Moro", Italy ${ }^{2}$
}

\begin{abstract}
The general practitioner is a link figure between the care needs of individuals and the rights of everyone to health protection and health promotion. Islamic patient, with his rich and strong symbolic traditions, represents a challenge for social inclusion. This paper focuses on the training needs of both physicians and Islamic patients.
\end{abstract}

\section{Introduction}

The present research project was aimed at the detection of training needs for general practitioners in relation to the patient of Islamic origin, and conversely, at the recognition of the needs of Muslim patient care.

The population examined was that of general practitioners belonging to FIMMG (Italian Federation of General Practitioners - Federazione Italiana Medici di Medicina Generale). There were taken into account the doctors who work in the city of Bari, who are to be 160 units in year 2011.

For reasons of economy it was calculated a significant sample of 57 units. In fact, in the city of Bari the importance of medical studies, each of whom holding between 500 and 1000 patients, ensured a significant set of answers, having previously foreseen the risk of failure in answering around $50 \%$.

This study process is summarized in the following table showing the various stages of sample size:

- Population: 160 ; reference value:100,00\%

- Optimal value for significant sample: 48, corresponding to $30,00 \%$ of population.

- Lowest value significance threshold: 32, corresponding to $20,00 \%$ of population.

- Administered questionnaires: 57

- $\quad$ Collected questionnaires: 57

- $\quad$ Elaborated questionnaires: 57.

\section{Research Rationale}

We chose to study our reference set by a selfadministered questionnaire, carried out thanks to the excellent assistance of Dr. Filippo Anelli, regional secretary of FIMMG Apulia, and of Dr. Giovanni Battista Sportelli, provincial secretary FIMMG Bari.
This questionnaire, consisting of 40 items, has been structured in three parts.

The first part consists of a personal data file, which calls, in particular, the type of team which the GP is part of.

The second part, consisting of 30 items, is about the relationship between the general practitioner and the Islamic patient, and is referred to the characteristics and difficulties of the patient.

The third part, consisting of 10 items, is about educational needs of the general practitioner on the therapeutic relationship with the Muslim patient.

\subsection{Inquiry phases}

2.1.1. Administration of questionnaires and data collection. The administration of the questionnaire has been performed by Dr. Pasquale Renna, who was adequately prepared for delivery approaches, for the protocol to follow in order to engage with general practitioners, and for the procedures about the storage of printed material.

The collected informations have been managed and treated in full respect of Italian privacy law (Law on privacy, n. 196 of 30/06/03).

This phase lasted 120 days and involved 57 doctors.

2.1.2. Data computation. After this phase, the research group has been engaged with mechanization of datas, through a process of manual data entry on a database built on Excel spreadsheets.

These spreadsheets were linked and managed with a double key (Id.det and Pin), reported in the SQL procedure and, by a report on SPSS platform, charts and tables have been designed (the latter with Pivot procedures).

This phase lasted 30 days.

2.1.3. Questionnaire results. The following results concern the critical aspects of the professional relationship between the general practitioner and the islamic patient. They need an educational reflection and a consequent didactical planning, which will be explained in chapter $n$. 2 of the present paper. 


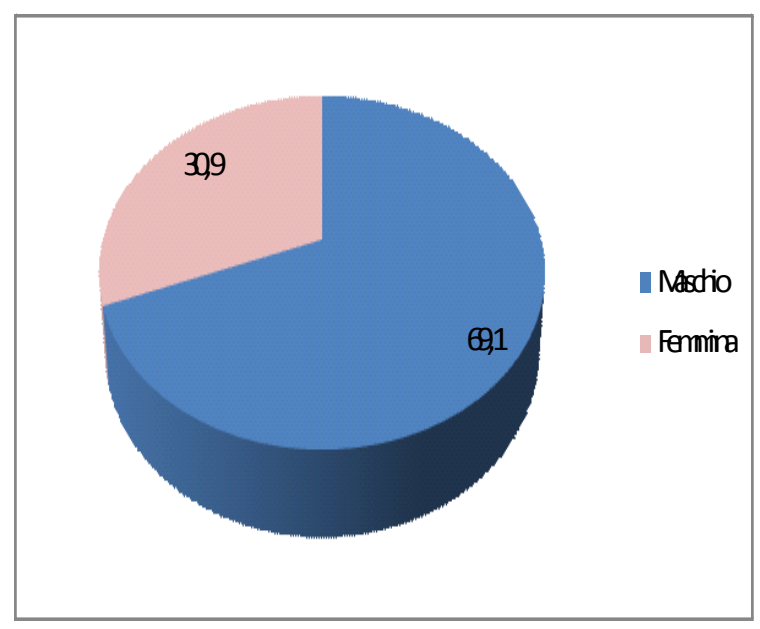

Figure 1. Percentage of the gender of interviewed general practitioners.

Comment: $69.1 \%$ of the interviewed practitioners are males. $30.9 \%$ of them are females.

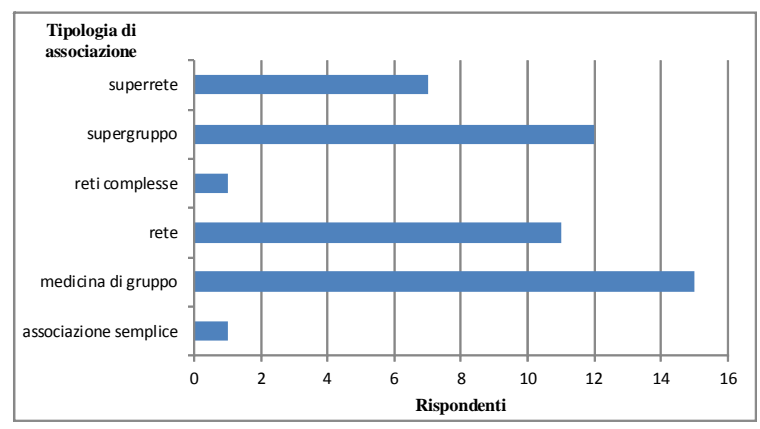

Figure 2. Kind of medical association which interviewed medical practitioners belonged to.

Comment: the registered kinds of medical association are: super-grid, super-group, complex networks, networks, group medicine, simple association. There is a prevalence of group medicine, which is a kind of association by which not only each practitioner is engaged in periodical meetings with a group of collegues, but also he/she is engaged in an effective supportive actions in management of patients.

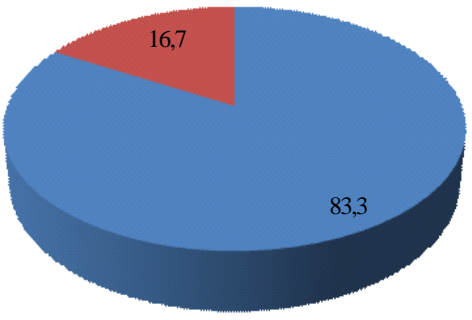

Figure 3. Percentage of the support staff.
Comment: $83.3 \%$ of the interviewed practitioners is assisted by support staff (nurse, secretary) who cares the reception of patient's requests.

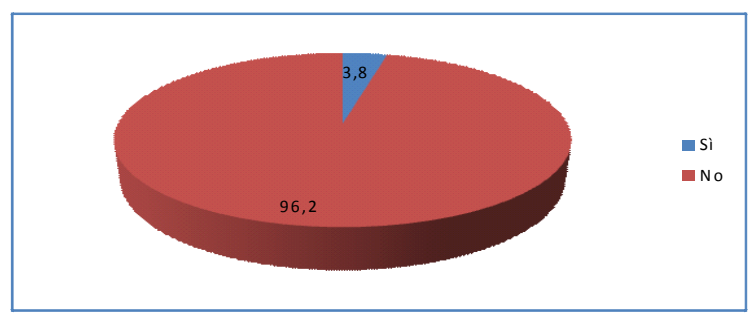

Figure 4. Percentage of the cultural mediator assistance.

Comment: $96.2 \%$ of the interviewed practitioners is not assisted by a cultural mediator. That has a particular significance in the case of Islamic patients: female ones are often accompanied by male relatives, who are directly involved in professional relationship with the family practitioner. Cultural mediator could help both males and females patient to undertake a direct relationship with the practitioner.

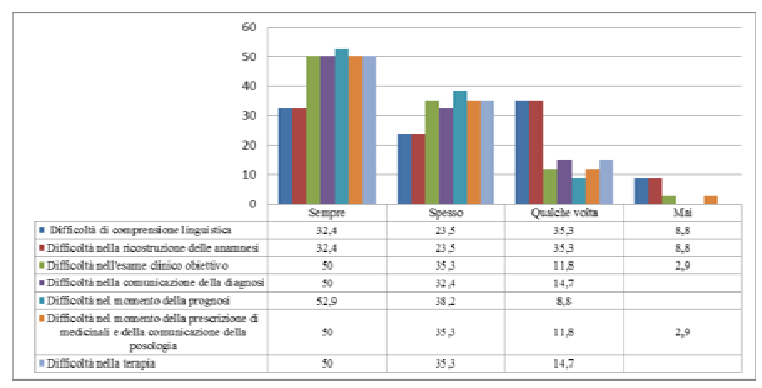

Figure 5. Difficulties of the general practitioner during the phases of the therapeutic relationship.

Comment: More of 50\% of the practitioners find difficulties in prognosis communication. About 50\% of the practitioners find difficulties during the clinical examination. It depends on both the cultural beliefs of Islamic patients (according to which human body is a God property and it has to be covered) and the objective lack of cultural mediators

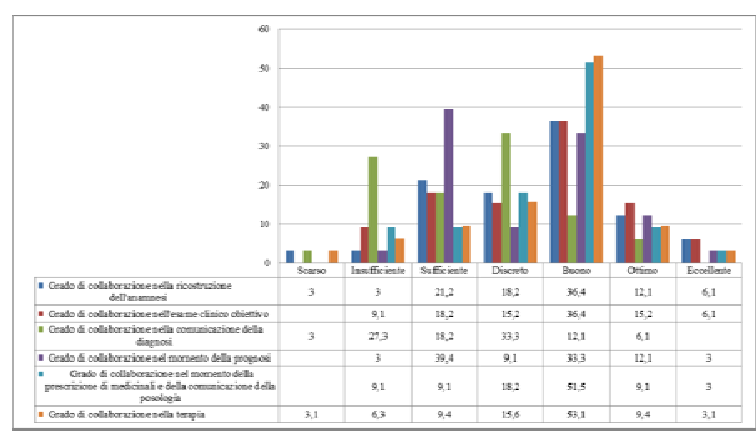

Figure 6. Level of cooperation of Islamic patient during the phases of the therapeutic relationship. 
Comment: $53.1 \%$ of the patients are collaborative in prescribed medicine assumption. That's why Koran encourages medical care.

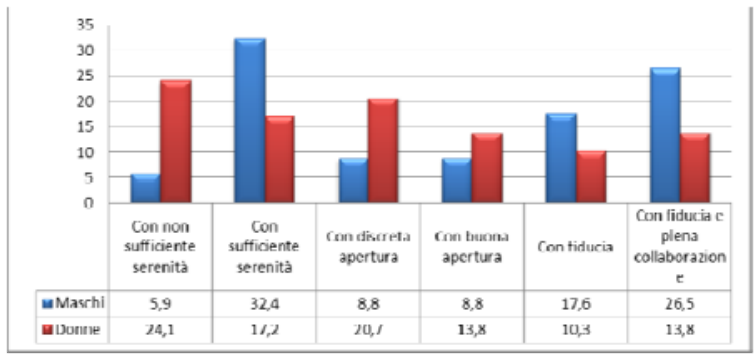

Figure 7. Males and females attitude during the medical examination.

Comment: while only $5.9 \%$ of males have difficulties during medical examination (undress, be touched, dress), $24.1 \%$ of females have serious difficulties. That's why female body, according to Islamic beliefs, is delegated to relative's safeguard (father's one in case of non-married women, husband's one in case of married women).

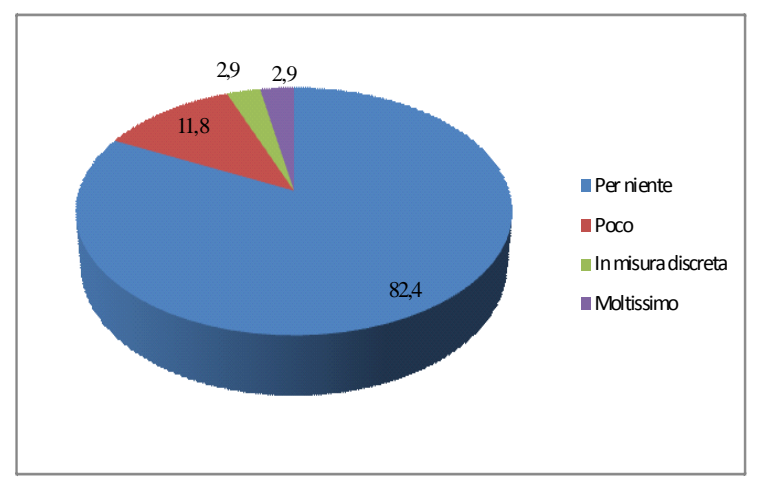

Figure 8. Percentage about difficulties in assumption of prescribed medicines.

Comment: $82.4 \%$ of interviewed practitioners say that Islamic patients does not have difficulties in medicine assumption. That's why, according to Islamic beliefs, human body has to be safeguarded by medical care. It is also interesting to notice that there is a sort of symbiosis between Western and Islamic cultures. During the Middle Ages both them growed together by sharing the common belief in God and the Greek scientific knowledge.

Now there is also a symbiotical relationship between them by sharing technological resources and energetical ones which run them.

Medical knowledge reveals to be very significant in order to grant a peaceful coexistence.

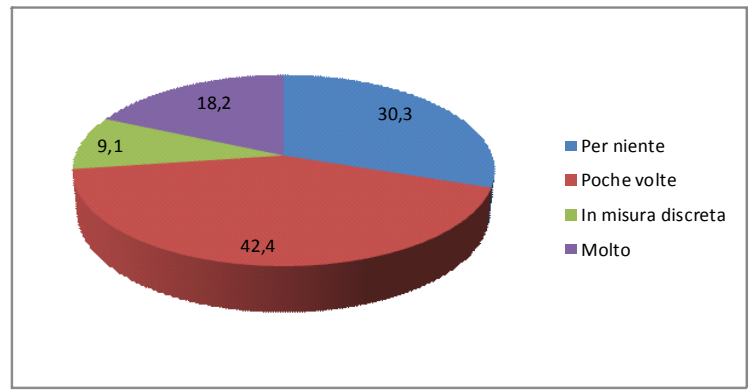

Figure 9. Level of incidence of islamic beliefs on the professional relationship and therapeutic success.

Comment: the previous datas are confirmed by these ones. $30.3 \%$ of the interviewed practitioners says that there is no incidence of Islamic beliefs on the professional relationship and therapeutic success. $42 . \%$ of them says that there is a very low incidence.

\section{Educational project about formation needs of family practitioners and care needs of Islamic patients}

Interviewed general practitioners required specific training in the knowledge of Islamic culture. In particular, they requested both a specifical university teaching on Islamic culture during the degree course in medicine (which in Italy is five years) and protocols for training on Islamic culture during the medical career.

Islamic patients, according to the results of the present research, need an educational training which make them able to explicit health diseases in a direct relationship with the general practitioner.

In order to help them, it is possible to prepare a specific workshop aimed at students of the third high school classes. It would be focused on sex education: one of the critical points of the questionnaire is the difference between males and females. In school it would be possible to set up a workshop on education to the respect and appreciation of gender difference through storytelling.

\section{References}

[1] Al-Awadi E., Al-Hashel J., Al-Hajeri D. (1999), Quranic faith-healing practices in Kuwait. Department of Community Medicine, Health Science Center, Kuwait University (unpublished report).

[2] Al-Baghdadi A. (1996). "The thought of Sayed Qutb: A critique”. Arab Journal for the Humanities, 56, 390-401.

[3] Al-Haddad, M. H., \& Al-Awfi, A. R. (1996). "History of the psychiatric hospital in Bahrain [Tarikh Moustashfa al-toub al-nafsi fil-Bahrain]”. Journal of the Bahrain Medical Humanities, 53, 62-99. 
[4] Al-Sayegh F. (1995). "Religious missions in the Emirates region: Medical service as a proselytizing instrument (1900-1949)" [Al-tabshir fi mintaqat al-imarat: Al-Khidmat al-toubiyat kawasilatin lil-tabshir 1900-1949]. Arab Journal for the Humanities, 53, 62-99.

[5] Al-Waii, T., Abu-Fadl, A., \& Al-Jundi, A. R. (1972). "Vol. 1: The digestive system" In Al-Awadi A. R. (Ed.), The Islamic Guide to Medical Theology [ Al-Musherd alIslami fi al-Fikh al-Tubi], 9-51.

[6] Bowers, J. Z. (1978). "Reception of acupuncture by the scientific community: From scorn to a degree of interest". Comparative Medicine East and West, 6, 89-96.

[7] Chow, E. P. Y. (1984). "Traditional Chinese medicine: A holistic system”. In W. J. Salmon (Ed.), Alternative medicines: Popular and policy perspectives, Tavistock, New York, 114-137.

[8] Dunlop D. M. (1955), Philosophical Predecessors and Contemporaries of Ibn Bajjah, in $<<\mathrm{IQ}>>, 2$.

[9] El-Sayyad, I. (1993). "The Islamic view of medicine”. In: Reflections on Islamic medicine (pp. 1-27). Durban, South Africa.

[10] Erez, S. (1981). Ottoman medicine viewed through western eyes. Hexagon, 9(S), 1-4.

[11] Esposito, J. L. (1992). "Islam and the State: Dynamics of the resurgence". In The Islamic threat: Myth or reality?, Oxford University Press, New York, 77-118.

[12] Frezzos, R. (1987). "Soft medicines”. In Health at any cost. (La santé a tout prix). Les dossiers du Canard, 23, 90-93.

[13] Friedman, T. L. (1989). "Hama rules”, in From Beirut to Jerusalem, Toronto: Collins Publishers.

[14] Gallagher, E. B. (1993). "Modernization and medical care”. In P. Conrad \& E. B. Gallagher (Eds.), Health and health care in developing countries. Philadelphia: Temple University Press.

[15] Gallagher, N. (1983). Medicine and power in Tunisia 1780-1900. Cambridge: Cambridge University Press.

[16] Gallelli, R. (1998). Salute cultura educazione. Bari: Mario Adda.

[17] Goldman, B. (1991). “Ayurvedism: Eastern medicine moves West”. Canadian Medical Association Journal, 1991, 9-12.

[18] Heng, M. B. \& Key, P. J. (1995). “Cambodian health in transition”. British Medical Journal, 311, 435-437.

[19] Jalal, O. (1999). Dialogue on healing with Coran [Hiwar hawla al-moualajat bil-Quraan]. Meraat al-Ommah, 1185, 16-19.
[20] Kronenfeld, J. J. \& Wasner, C. (1982). "The use of unorthodox therapies and marginal practitioners”. Social Sciences \& Medicine, 16, 1119-1125.

[21] Nanji A. A. (1988). "Medical ethics and the Islamic tradition”. Journal of Medicine and Philosophy, 13, 257275.

[22] Pinto Minerva, F. (2008). L'intercultura. Roma-Bari: Laterza. 